\title{
Preparing anesthesiology faculty for competency-based medical education
}

\section{Introduction de la formation médicale fondée sur les compétences en anesthésiologie: comment préparer le corps professoral?}

\author{
Amy B. Fraser, MD, MHPE (D) Emma J. Stodel, PhD • Robert Jee, MD • \\ Daniel A. Dubois, MD • Alan J. Chaput, MD, PharmD
}

Received: 10 April 2016/Revised: 15 August 2016/Accepted: 12 September 2016/Published online: 19 September 2016

(c) Canadian Anesthesiologists' Society 2016

\begin{abstract}
Purpose Competency-based medical education (CBME) is quickly becoming the dominant organizing principle for medical residency programs. As CBME requires changes in the way medical education is delivered, faculty will need to acquire new skills in teaching and assessment in order to navigate the transition. In this paper, we examine the evidence supporting best practices in faculty development, propose strategies for faculty development for CBMEbased residency programs, and discuss the results of faculty development initiatives at the pioneering anesthesia $C B M E$ residency program at the University of Ottawa.

Source Review of the current literature and information from the University of Ottawa anesthesia residency program.

Principal findings Faculty development is critical to the success of CBME programs. Attention must be paid to the competence of faculty to teach and assess all of the CanMEDS roles. At the University of Ottawa, some faculty development initiatives were very successful, while others
\end{abstract}

\footnotetext{
A. B. Fraser, MD, MHPE ( $\square)$

Department of Anesthesiology, Ottawa Civic Hospital, The Ottawa Hospital/The University of Ottawa, Suite B302, 1053 Carling Avenue, Ottawa, ON K1Y 4E2, Canada

e-mail: afraser@toh.on.ca

\section{E. J. Stodel, $\mathrm{PhD}$}

The Office of Postgraduate Medical Education, University of Ottawa, Ottawa, ON, Canada

E. J. Stodel, PhD

Learning 4 Excellence, Ottawa, ON, Canada

R. Jee, MD - D. A. Dubois, MD - A. J. Chaput, MD, PharmD Department of Anesthesiology, The Ottawa Hospital/The University of Ottawa, Ottawa, ON, Canada
}

were hindered by factors both internal and external to the residency program. Many faculty development activities had low attendance rates.

Conclusions Faculty development must be considered in the rollout of any new educational initiative. Experts suggest that faculty development for CBME should incorporate educational activities using multiple teaching and delivery methods, and should be offered longitudinally through the planning, development, and implementation phases of curriculum change. Additionally, these educational activities must continue until all faculty have demonstrated an acceptable level of competence. Faculty buy-in is paramount to the successful delivery of any faculty development program that is not mandatory in nature.

\section{Résumé}

Objectif La formation médicale fondée sur les compétences (FMFC) est en passe de devenir le principe organisationnel dominant des programmes de résidence en médecine. Toutefois, la FMFC nécessite des modifications de la façon d'enseigner la médecine, et le corps professoral devra acquérir de nouvelles compétences en enseignement et en évaluation afin que la transition se fasse sans heurt. Dans cet article, nous examinons les données factuelles sur lesquelles reposent les meilleures pratiques en matière de formation professorale; nous proposons ensuite diverses stratégies pour former le corps professoral aux programmes de résidence fondés sur la FMFC, avant de discuter des résultats des initiatives de perfectionnement professoral mises en place dans le cadre du premier programme de résidence de FMFC en anesthésie, à l'Université d'Ottawa.

Source Revue de la littérature actuelle et renseignements tirés du programme de résidence en anesthésie de l'Université d'Ottawa. 
Constatations principales La formation professorale est un élément crucial à la réussite des programmes de FMFC. Il faut porter une attention particulière à la compétence $d u$ corps professoral en ce qui touche à l'enseignement et à l'évaluation de tous les rôles CanMEDS. À l'Université d'Ottawa, certaines initiatives de formation professorale ont rencontré un franc succès, alors que d'autres ont, en revanche, été mises à mal - tant par des facteurs internes qu'externes au programme de résidence. Le taux de fréquentation de plusieurs activités de formation professorale était faible.

Conclusion La formation professorale doit faire partie intégrante du déploiement de chaque nouvelle initiative éducationnelle. Selon les experts, la formation professorale pour la FMFC devrait intégrer des activités éducationnelles fondées sur plusieurs méthodes d'enseignement et de transmission du savoir et devrait être offerte tout au long des phases de planification, de mise au point et de mise en cuvre des changements au programme d'enseignement. En outre, ces activités éducationnelles doivent se poursuivre jusqu'à ce que le corps professoral dans son intégralité ait fait preuve d'un niveau acceptable de compétence. L'appui $d u$ corps professoral est essentiel à la réussite de tout programme de perfectionnement professoral qui n'est pas de nature obligatoire.

Medical education the world over is experiencing a paradigm shift to competency-based medical education (CBME). The Royal College of Physicians and Surgeons of Canada (RCPSC) has launched Competence by Design (CBD) as their outcomes-based approach for residency training and specialty practice. ${ }^{1}$ Over the upcoming years, all specialty programs in Canada will transition to CBD. On July 1, 2015, the Department of Anesthesiology at the University of Ottawa implemented a CBME program. ${ }^{2,3}$ In this paper, we discuss the need for faculty development when implementing CBME, outline our efforts to prepare faculty to teach and assess residents within this new training paradigm, and share our experiences preparing faculty for CBME.

\section{What is faculty development?}

Faculty development refers to any planned activities designed to improve an individual's knowledge, skills, and attitude in areas related to the roles and responsibilities of a faculty member (e.g., education, research, administration) at all levels, from the individual learner to the broader educational system. ${ }^{4-6}$
A literature review of faculty development initiatives designed to improve teaching effectiveness in medical education was conducted using MEDLINE $\AA$ as the primary database and using the search terms "competency based medical education" and "faculty development". This review revealed the following outcomes, as summarized by Steinert et al. $(2006)^{7}$ :

- Faculty members have high overall satisfaction with faculty development, finding it "acceptable, useful, and relevant to their personal objectives".

- Faculty development is effective in improving motivation for teaching and in developing appreciation for the benefits of faculty development.

- Faculty development can improve faculty knowledge, skills, and behaviour.

- Faculty development has an impact at the organizational level, with faculty becoming more involved in new educational activities as a result of their participation.

More specifically, in relation to the skills required to teach and assess in a CBME program, studies have revealed that faculty development can improve skills in direct observation, with changes in behaviour persisting up to eight months, ${ }^{8}$ as well as elicit changes in assessment practice. ${ }^{9}$

\section{What is CBME?}

A CBME paradigm involves identifying the abilities required of physicians and then designing curriculum to support the achievement of these predefined competencies. ${ }^{10}$ This approach defies the assumption that competence to practice as a physician is achieved solely based on time spent on rotations - that is, through an onthe-job training and/or an apprenticeship model ${ }^{11}$-and instead requires residents to demonstrate the competencies deemed necessary for patient care. By definition, this approach will require a robust and multifaceted assessment system. ${ }^{12}$ The terms "assessment" and "evaluation" are often used interchangeably by faculty; however, in this paper, these terms are used as per the definitions used in the medical education literature. Accordingly, the word "assessment" is used to describe the collection of information to provide feedback and guide the learner to the next level, whereas "evaluation" is used to refer to the making of a judgement on the information collected (e.g., whether or not a trainee has achieved competence in a given area).

The CBME curriculum at the University of Ottawa Anesthesia program is considerably different than its former time-based curriculum. A complete description of 
the CBME curriculum and its development has previously been published. ${ }^{2,3}$

Briefly, the Ottawa CBME program is divided into four main components: Transition to Discipline, Foundations of Discipline, Core of Discipline, and Transition to Practice. The academic year is divided into 13 four-week blocks. The Transition period (one block) functions as an introduction to the operating room and anesthesia practice. This is followed by the Foundations period (six blocks) where time is divided between clinical anesthesia practice and non-clinical activities, including learning sessions (both independent and expert-led) and frequent simulation sessions. Notably absent in the CBME curriculum are the first-year "offservice" (i.e., non-anesthesia) rotations. Core of Discipline comprises the bulk of the curriculum with 39 blocks of both anesthesia and non-anesthesia rotations. During the Core period, residents receive serial exposure to various areas of anesthesia practice. Finally, Transition to Practice is a sixblock period during which time residents are given increasing independence. The CanMEDS intrinsic roles (Communicator, Collaborator, Professional, Leader, Health Advocate, and Scholar) ${ }^{13}$ are assessed longitudinally throughout the program. Importantly, the Ottawa Anesthesia CBME program is a pilot program in which residents can complete their training in only four years, whereas almost all other specialty programs plan to preserve the current length of training for their transition to CBME.

Traditional "academic time" for residents has been replaced by group learning activities, online case-based learning, and regular exposure to both low- and highfidelity simulation. Successful progression through the program requires demonstration of competence at each level. In order to determine resident competence, considerable faculty involvement is required, most notably in the form of frequent resident assessment via electronic platforms (such as the platform used for daily assessment of residents - see a video tutorial for this platform at https://youtu.be/k6-Gj8ZDjhs.

\section{The importance of faculty development for CBME}

A major challenge to the implementation of CBME is the need for faculty development around the teaching and assessment of resident competencies. ${ }^{14}$ Despite long being responsible for delivering resident education, many faculty lack formal training in teaching and assessment. ${ }^{15}$ This lack of training has been problematic in the past. For example, Sterkenburg et al. ${ }^{16}$ found that, as raters, anesthesiologists showed high variability when deciding whether residents were competent at performing selected tasks independently. Others have shown that faculty struggle to identify gaps in learners' competence, ${ }^{17}$ use assessment instruments inconsistently and have trouble interpreting the findings, ${ }^{18}$ and vary greatly with respect to their standards for and expectations of residents. ${ }^{19}$ Moreover, the advent of CBME requires that teachers and evaluators "gain a new understanding of the theory and practice of education, one that is different from that demanded of them by content- and time-based systems". 4

It has been argued that, if CBME "is to have a ghost of a chance, it will require faculty buy-in and massive amounts of faculty development". ${ }^{20}$ Faculty development can be a strategy to facilitate buy-in and commitment. Educating faculty around the purpose, objective, and rationale of CBME will be critical for successful implementation. ${ }^{21}$

\section{What faculty development is needed for CBME?}

As CBME is a new paradigm in medical education, faculty must understand both the theory supporting this approach and its grounding in competencies if they are to teach within this model. ${ }^{22}$ Faculty will be required to "take on new roles to coach residents progressing through the milestones and assess their achievements." ${ }^{23}$ The core principle of CBME is that residents must demonstrate competence along a defined development continuum. Faculty, therefore, must be able to assess learners effectively against objective criteria. In addition, faculty must become accustomed to doing so on a regular basis, ${ }^{24}$ which is in contrast to the traditional model where residents are typically assessed infrequently and evaluated at the end of a rotation using subjective and nonstandardized measures. $^{4}$

In essence, CBME requires a shift in the teaching paradigm -i.e., from a model that is predominantly knowledge-focused to one that is competency-based. ${ }^{24}$ Competency-based medical education has clear outcomes that allow residents to drive their own learning and seek out the learning opportunities they require to address gaps in competence. The role of the teacher thus shifts from one of content expert and transmitter of knowledge to one of guide or facilitator. ${ }^{25}$ Thus far, the teacher held sole responsibility for the content; however, teacher and learner will now share this responsibility. The teacher must plan and sequence learning experiences that will allow the learner to develop skills in the correct progression as well as manage the instructional resources. ${ }^{26}$ Teachers will need to employ active learning strategies that engage the learner in the experience and promote critical thinking and application of knowledge rather than knowledge acquisition. Teachers will face the challenge of slipping back to "teaching as we were taught", and thus, ongoing faculty development is required. Further, there is the expectation that faculty become effective change agents and transform medical education and the way healthcare is delivered. ${ }^{24}$ 
Evidence suggests that faculty are currently insufficiently prepared for this task ${ }^{10,27}$ and will need to learn new teaching and assessment strategies in order to provide optimal support for the learner-centred approach required by CBME. ${ }^{14}$ Work-based assessment using direct observation and provision of frequent formative feedback ${ }^{28}$ form the cornerstone of CBME. Thus, faculty will need to develop and apply valid and reliable strategies to provide the "authentic and regular assessment that is an essential aspect of CBME". 6 The requirement for frequent assessments has some faculty concerned, given that assessment can be resource intensive.

In planning faculty development, medical educators often assume that faculty already possess sufficient expertise in the competencies they will be teaching and assessing in trainees. Several authors have pointed out that some faculty are identifiably incompetent in some areas of medical expertise. ${ }^{27,29-32}$ The clinical skills of faculty members may also have an influence on their ability to assess learners. ${ }^{33}$ Therefore, faculty development may also need to focus on the support of medical expertise among faculty members through competency-based continuing professional development.

Further, in addition to teaching competencies in the medical expert role, faculty must be able to teach and assess competencies pertaining to other domains of practice. ${ }^{4}$ For example, the CanMEDS framework delineates competencies in the roles of Communicator, Collaborator, Leader, Health Advocate, Scholar, and Professional. $^{34}$ Similarly, the Accreditation Council for Graduate Medical Education in the United States defined the core competencies of Patient Care, Professionalism, Interpersonal and Communication Skills, Practice-Based Learning and Improvement, and SystemBased Practice, in addition to that of Medical Knowledge. Competency-based medical education requires faculty who are not recent graduates to teach and assess competencies they were never formally taught themselves. ${ }^{14}$ Further, they may not necessarily value these competencies highly. ${ }^{20,35}$

For CBME to be effective, there is a need for successful leaders who can serve as educational mentors for the rest of the faculty. ${ }^{6}$ Faculty development is a tool for developing such leaders and thus for promoting the organizational change required for the implementation of this new paradigm of education. ${ }^{27}$ Indeed, faculty development has been shown to be effective in changing culture within organizations and promoting innovation. ${ }^{6,7,36}$

\section{Faculty development to support CBME at The University of Ottawa}

The need for change management with the implementation of CBME was the primary driver of our faculty development program. Change management involves identifying resources that will support change, barriers that will inhibit change, environmental factors that will affect planning, and strategies to navigate the transition. ${ }^{37}$ A change management analysis may require the services of a professional facilitator with training in business administration. The Strengths, Weaknesses, Opportunities, and Threats (SWOT) analysis conducted during our program planning phase revealed a key issue, specifically, a perception of "lack of competence" among faculty to deliver an outcomes-based program. In particular, faculty were concerned they lacked proficiency in the following areas:

- Required knowledge and skills to shift the program from a traditional passive learning approach to one that uses active learning strategies;

- Technological expertise required for teaching and assessing in a CBME program (e.g., managing online tools);

- Ability to assess residents reliably; and

- Time to assess residents frequently.

In view of the above, one of the key success factors identified for the CBME program was faculty development to enhance faculty members' confidence to implement CBME. Specifically, we made plans to:

- Develop a program for regular faculty development in preparation for implementation of CBME;

- Develop user-friendly templates to facilitate the development of curriculum;

- Provide curriculum and technology support for faculty; and

- Develop simplified assessment tools to improve acceptability of the increased number of assessments required with $\mathrm{CBME}$.

As a result, we targeted faculty development at three main groups of faculty: thought leaders, curriculum developers, and clinical teaching staff (see Fig. 1). Faculty development started three years before program launch, with a focus on change management, and was ongoing through implementation.

\section{Thought leaders}

As per the previously developed strategy for change management, support for curricular change was recruited at all levels. Endorsement from key leadership in the department and hospital was sought early to help promote acceptance by all faculty. ${ }^{27}$ Departmental faculty interested in medical education were then approached for their support as "thought leaders". 27 The purpose of recruiting thought leaders was to decentralize the delivery of CBME- 
related faculty development, that is, to spread the word by many rather than using a centralized approach built around formal faculty development sessions. This approach acknowledged that influential and respected faculty who are "in the trenches" can serve as valuable resources for other faculty in everyday work settings. Thought leaders can provide ongoing knowledge dissemination and visible support for CBME that will promote wider engagementan essential element for the success of CBME. ${ }^{4,32}$

\section{Curriculum developers}

The core of our CBME program is structured around 13 subspecialty modules (e.g., thoracic anesthesia, acute pain) and six modules covering the intrinsic (non-Medical Expert) CanMEDS roles of Leader, Professional, Communicator, Collaborator, Scholar, and Health Advocate. Subspecialty and intrinsic role experts were recruited as Module Leads and were responsible for refining the entrustable professional activities (EPAs) and milestones for their module as well as designing the curriculum and assessment approaches to support the achievement of these milestones. Entrustable professional activities are tasks that can be delegated to a resident in a clinical context once the resident has shown sufficient competence to perform the given task, for example, management of cardiac surgery using cardiopulmonary bypass. Each EPA typically comprises several milestones (e.g., place and interpret an arterial line), which are observable markers of an individual's ability along a developmental continuum. ${ }^{38}$

Module Leads then recruited other faculty to help them in their curriculum development efforts. All Module Leads had the support of an educational expert sponsored by the Office of Postgraduate Medical Education to help in the development of assessment tools and curriculum. Subspecialty experts were also paired with a simulation expert from the department to assist with the development of simulation-based teaching and assessment tools.

In our CBME program, we replaced residents' academic half-days with online learning cases. The learning cases are based on the format of the RCPSC oral examinations and are used to assess the residents' medical knowledge and critical thinking. Residents are provided with a case scenario followed by questions to direct their learning as well as selected resources (e.g., journal articles, textbook chapters, videos, learning activities). Residents engage in self-directed learning and then meet with a staff anesthesiologist for assessment on the case. Additional information on these aspects of self-directed learning can be found in Stodel et al. $(2015)^{3}$ or at https://youtu.be/ OLirP-QjFQA.
The principles of CBME and curriculum development were new to many of the Module Leads, and thus faculty development was essential in these areas. Fifteen months prior to program launch, a one-day retreat was organized for Module Leads to ensure a comprehensive curriculum design across modules, provide guidance on curriculum development, and finalize a template for learning case development. A second retreat, which took place nine months prior to the commencement of the CBME program, addressed the timeline for CBME curriculum development, the electronic platforms for teaching and assessment, formalization of module overview and expectations, and review of learning case expectations.

\section{Clinical teaching staff}

While a core group of faculty were involved in the design and development of the CBME program, its implementation required involvement of the entire departmental faculty. The following topics are included amongst those we identified for faculty development:

1. CBME: What is it, and what is the rationale for curricular change?

2. What will be the day-to-day expectations of faculty following implementation of the new curriculum?

3. How will faculty learn to use new assessment tools?

4. What skills will faculty need for critically observing and assessing learners?

5. How will faculty provide effective feedback, especially when it needs to be corrective? $?^{4,27,28,39}$

Faculty were introduced early to the concept of CBME and its impact on their day-to-day teaching and assessment, often through grand rounds presentations. We found this to be the most effective approach for gaining a wide audience. Presenters included our CBME leadership team, as well as the program director from the University of Toronto orthopedic surgery residency program (the first CBME residency program in Canada). Frequent messaging via email bulletins was also employed to keep faculty updated on program development and the expected changes associated with CBME.

The year prior to program launch, our annual faculty development day was dedicated to feedback and assessment. The new electronic daily assessment platform, the Clinical Case Assessment Tool (CCAT), was unveiled (for more information see Stodel et al. $(2015)^{3}$ or https://youtu.be/k6-Gj8ZDjhs), and guest presenters offered workshops on giving feedback and having difficult teacher-learner conversations. The topic of assessment was further addressed through a workshop designed to improve the quality of written feedback in the CCAT. The department employed other faculty 
development approaches, including the development of video tutorials for the online tools (over 140 views each) and a pub trivia evening pertaining to the CanMEDS intrinsic roles. Whereas faculty conferred positive evaluations for the above sessions, attendance was low, ranging from $10-30 \%$ of faculty members. Fig. 1 provides a summary of the faculty development activities for our CBME program.

In preparation for the transition to CBME across all residency programs, the Office of Postgraduate Medical Education at the University of Ottawa created a series of ebooks on teaching and assessing the intrinsic CanMEDS roles (available on iTunes using the search term "University of Ottawa Faculty of Medicine") as well as complementary workshops. The Office of Faculty Development at the Faculty of Medicine also developed online modules designed to enhance feedback skills, assessment skills, and evaluation of learners (https://learn.med.uottawa.ca/ continuing-professional-development).Very few anesthesia faculty have taken advantage of these resources, likely because completion of these modules was not mandatory.

\section{Successes and challenges at the University of Ottawa}

Perhaps the biggest success of our faculty development program was enlisting the support of respected faculty to help implement change and promote broad and rapid uptake by other faculty. ${ }^{27}$ As Dath and Iobst ${ }^{4}$ have noted, "without the acceptance and support of teachers themselves, CBME will not survive." Specific successes included the large number of faculty actively engaged in curriculum development as well as the successful implementation of the new assessment tools and electronic teaching and assessment platforms.

Nevertheless, commitment to faculty development was low outside the core CBME group, with poor attendance at many of the organized events, which were attended on a voluntary basis. The events were often scheduled during weekends, holidays, or evenings to minimize interruptions to patient care and maximize opportunities to attend. Even so, competition between faculty development and personal time was likely an important reason for low attendance at events other than grand rounds and retreats. As Holmboe et al. (2010) ${ }^{8}$ have suggested, incentives for completion of faculty development activities might be necessary in order to maximize participation. Improving accessibility of faculty development materials could also be achieved by offering materials online. For example, recordings of grand rounds and guest speaker presentations as well as standalone online modules could be tracked for completion and linked to faculty becoming "certified" to work with CBME learners.

Post hoc, it is clear that optimal faculty development was hindered by factors external to the program itself, particularly departmental leadership and program costs. Our department experienced changes in leadership leading up to program implementation, including the departmental chief/chair, vice-chair of education, program director, associate program director, and faculty development director. Although all were supportive of the transition to CBME, the program in general and faculty development in particular would have benefited from more continuity in leadership.

Despite the enormous amount of work required for innovation and new curriculum development, we were originally advised that CBME would provide cost savings in the long run, largely through decreased training time. Our hope was that these cost-saving opportunities would lead to financial backing from governing bodies, which would offset program start-up costs. Owing to unexpected fiscal changes at our targeted funding sources, we were unable to secure the expected financial support for the program. The amount of planning and faculty development led to considerable overspending within our budget. Running a deficit in a burgeoning academic department has left the burden of additional (unpaid) work on the backs of medical educators and the departments who support them. One solution for mitigating both costs and loss of developers' personal time would be to share innovations within educational networks. Institutions must provide the oversight and resources necessary to ensure a smooth transition to CBME. ${ }^{27}$ Ideally, resources would be provided and shared by the university or by national specialty education committees.

Several factors intrinsic to the process of faculty development were identified as areas for potential improvement. A common theme for both faculty members and departmental leadership was confusion about faculty development, its purpose, and its planning. More frequent formal and informal communication from CBME leaders to all stakeholders would likely have improved understanding of the rationale behind faculty development and may have improved attendance at faculty development events. One suggestion for informal communication was the creation of a web-based pre-launch timeline for CBME showing completed tasks, pending tasks, and deadlines in order to improve department-wide understanding of what was needed to create readiness for CBME and how individuals could contribute.

Selected benefits and challenges for CBME-related faculty development are summarized in the Table and depicted in Fig. 1.

\section{Next steps}

The lessons from our experience at the University of Ottawa as well as faculty development best practices 


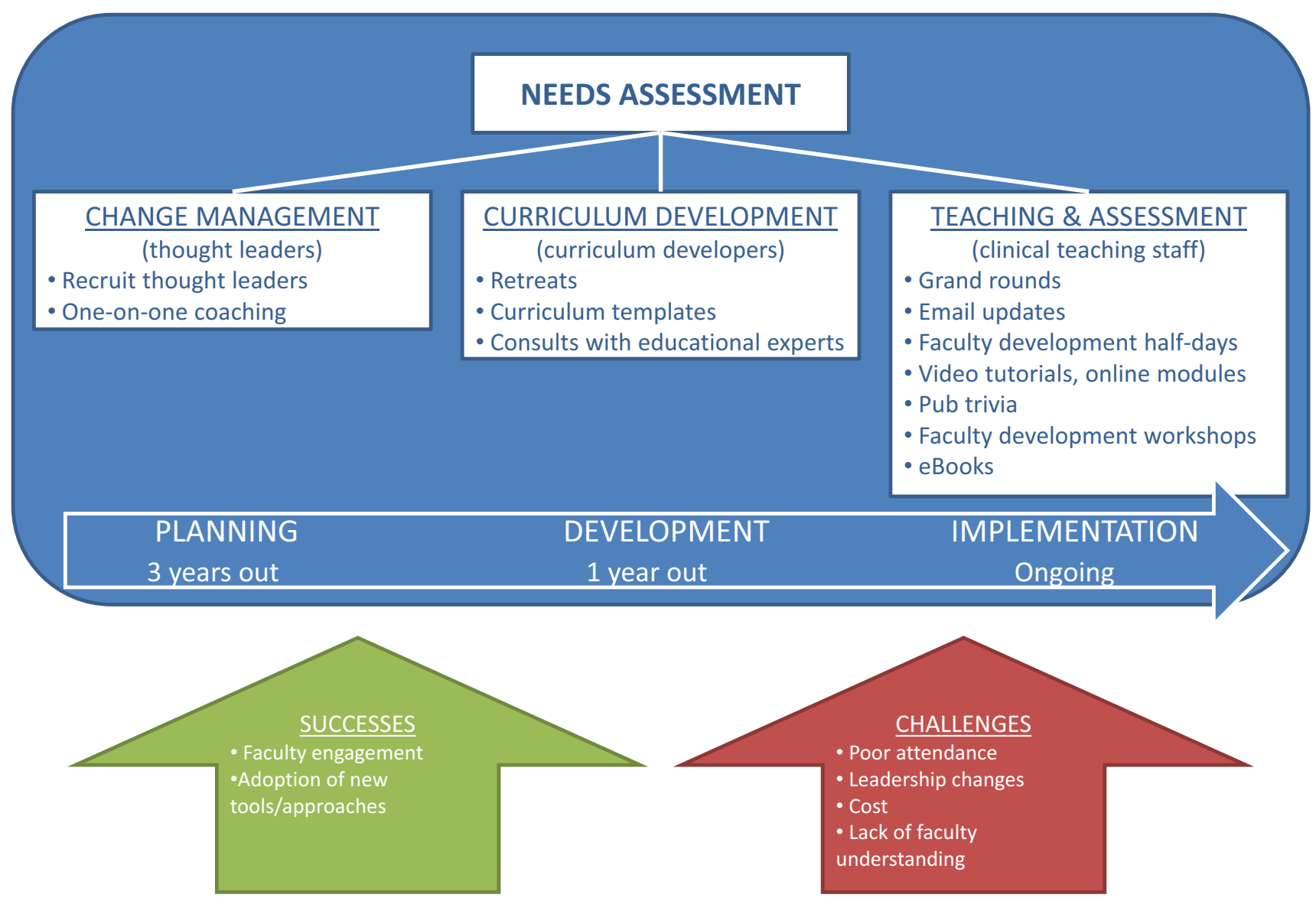

Fig. 1 The process of designing a faculty development program, from needs assessment through planning, development, and implementation. Specific groups of faculty members are targeted at each stage

identified in the medical education literature will be used to guide our future faculty development efforts. Fig. 2 illustrates a suggested approach to faculty development for CBME based on these "lessons learned".

It is necessary to provide a longitudinal faculty development program, as the one-time "bolus" effect quickly wanes. ${ }^{40}$ As noted by Holmboe et al. (2011), ${ }^{27}$ it is no longer acceptable to perform faculty development as a "one-off" activity that is inadequately supported. A continuous pathway for development is especially important for those faculty whose teaching and assessment skills need improvement. ${ }^{41}$ This will involve feedback to faculty about how their assessment skills compare with local and national benchmarks ${ }^{27,42}$ and, in some instances, with individualized learning programs. ${ }^{6}$ One of our next faculty development initiatives will involve providing faculty with feedback on the quality of the daily assessments they complete and increasing the amount of faculty evaluations to be submitted by the learner. Taking a longitudinal viewpoint, we plan ongoing use of social media, monthly communiqués, and development of online resources within the department website.
We also need to focus on increasing the attendance at faculty development sessions. Faculty members have many responsibilities competing for their professional time, including patient care, research, teaching, and administration. They have limited time for developing their teaching skills. ${ }^{43}$ Faculty development initiatives need to be sensitive to this reality and recognize and reward faculty for their involvement. ${ }^{6}$

Participation in faculty development is often volunteer based. Steinert et al. (2006) ${ }^{7}$ suggested that it may be time to "move beyond 'volunteerism' as we strive to enhance teaching and learning" and consider mandatory participation in faculty development. Alternatively, faculty development could be linked to clinical learning needs or administrative and regulatory requirements as a way to provide incentives for faculty participation and enhance efficiency. ${ }^{44}$

Additionally, the role of the educator has historically been the "unsung hero" of academia. To entice faculty to participate in CBME implementation, universities may need to consider re-examining the criteria used for academic promotion. Steinert has stated that, at the 
Table Benefits and challenges of faculty development for CBME

\begin{tabular}{|c|c|}
\hline Benefits & Challenges \\
\hline $\begin{array}{l}\text { - Promote changes in behaviour and attitudes } \\
\text { - Increase motivation for teaching } \\
\text { - Develop knowledge and skills with regard to teaching and } \\
\text { assessment strategies } \\
\text { - Improve inter-rater reliability of assessments } \\
\text { - Normalize standards and expectations of resident performance } \\
\text { - Promote organizational change }\end{array}$ & $\begin{array}{l}\text { - Faculty members' resistance to changing/expanding roles with } \\
\text { introduction of CBME } \\
\text { - Local rather than collective approach to faculty development } \\
\text { - Lack of time for faculty to engage in faculty development activities } \\
\text { - Lack of incentives for faculty to participate in faculty development } \\
\text { activities } \\
\text { - Cost of design, development, and implementation of faculty } \\
\text { development activities }\end{array}$ \\
\hline
\end{tabular}

CBME = competency-based medical education

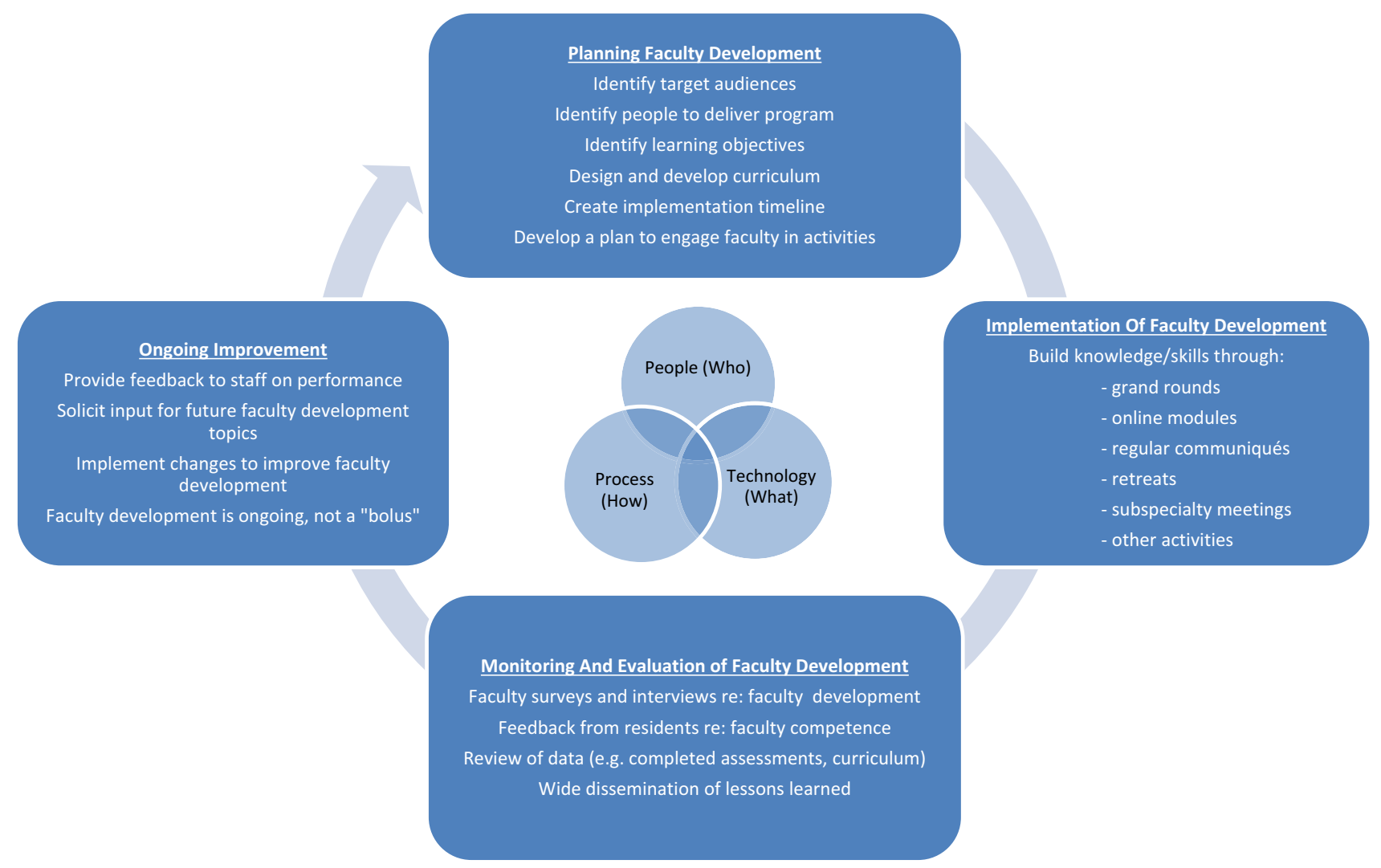

Fig. 2 Organizing faculty development for change management: a suggested approach to development, implementation, evaluation, and maintenance of a faculty development program in any environment where change management is desirable

organizational level, faculty development initiatives should help to value and promote educational scholarship in postgraduate medical education (including the scholarship of teaching) and recognize teaching excellence and educational scholarship in promotion criteria. ${ }^{6}$

Clearly, the creation of a comprehensive faculty development initiative needs to be properly supported with financial and other resources. Rather than individual departments and institutions tackling this enterprise in silos, we support Holmboe et al.'s $(2011)^{27}$ call for an "urgent ... international initiative of faculty development around CBME and assessment". While we await the optimal faculty development program that suits the needs of all programs, our representative bodies (i.e., the Canadian Anesthesiologists' Society and the Association of Canadian University Departments of Anesthesia) need to work together. Our collaborative efforts to share and develop the tools necessary for CBME implementation will make the CBME transition for anesthesia a success. 


\section{Conclusion}

The need for faculty development in postgraduate medical training programs has never been greater, particularly as the Royal College embarks on its multi-year transition to a competency-based training model for residency education. Our faculty will need not only to be taught the fundamental concepts underlying competency-based training but also to be trained to be effective teachers and assessors of medical expertise and the intrinsic CanMEDS roles. As seen in any area where change is imposed on a group of people, some (faculty) will openly embrace the change, while many will be reluctant. Faculty development activities must be designed to include both such groups. A change management strategy, such as SWOT, may help predict obstacles to change and manage resources to support the transition.

In order to be most effective, faculty development activities must be planned well in advance of the start of the change event, delivered in a variety of ways, and provided on an ongoing basis. Nevertheless, our experience with the implementation of CBME in the anesthesiology program has shown us that a well-designed program is not enough to ensure success. There may be a role for mandatory faculty development activities to ensure all faculty involved in the education of our trainees are minimally competent, not only in their knowledge of CBME but also in how to teach and assess in this new model of education.

As we embark nationally in a change management cycle towards CBME, we will need to define the future determinants of our success. As mentioned above, faculty development initiatives have been shown to improve faculty satisfaction, motivation, and skills for teaching. ${ }^{7}$ For CBME, the ultimate goal of faculty development will be an improvement in learners' skills, attitude, and behaviour. The evidence for these outcomes has yet to be clearly established in large trials; therefore, with our planned implementation of CBME, it would be prudent to seek the relationship between faculty development and learner outcomes. This will require careful definitions of proposed outcomes, planning for evaluation at the inception of new programs, and collaboration with our research colleagues. To accomplish our objectives for scholarly work in this domain, we should strongly consider collaboration through local and national networks to develop and implement a collective research agenda both within and between specialties.

Acknowledgements The authors would like to acknowledge the work of Dr. Viren Naik, previous Vice-Chair of Education, Department of Anesthesiology, The University of Ottawa who conducted the SWOT analysis for our CBME program.

Funding Salary support for this work was provided by the Department of Anesthesiology at the University of Ottawa. The development of educational materials described in this paper was supported by the Office of Postgraduate Medical Education at the University of Ottawa.

\section{Conflicts of interest None declared.}

Author contributions Amy B. Fraser, Emma J. Stodel, Robert Jee, Daniel A. Dubois, and Alan J. Chaput contributed substantially to all aspects of the manuscript, including conception, design, literature review, and drafting the article.

Editorial responsibility This submission was handled by Dr. Hilary P. Grocott, Editor-in-Chief, Canadian Journal of Anesthesia.

\section{References}

1. Royal College of Physicians and Surgeons of Canada. About Competence By Design. Available from URL: http://www. royalcollege.ca/rcsite/cbd/competence-by-design-cbd-e (accessed August 2016).

2. Fraser AB, Stodel EJ, Chaput AJ. Curriculum reform for residency training: competence, change, and opportunities for leadership. Can J Anesth 2016; 63: 875-84.

3. Stodel EJ, Wyand A, Crooks S, Moffett S, Chiu M, Hudson CC. Designing and implementing a competency-based training program for anesthesiology residents at the university of Ottawa. Anesthesiol Res Pract 2015. DOI:10.1155/2015/713038.

4. Dath D, Iobst W. The importance of faculty development in the transition to competency-based medical education. Med Teach 2010; 32: 683-6.

5. Sheets KJ, Schwenk TL. Faculty development for family medicine educators: an agenda for future activities. Teach Learn Med 1990; 2: $141-8$

6. Steinert $Y$. Faculty Development for Postgraduate Education The Road Ahead. Members of the FMEC PG Consortium; 2011. Available from URL: https://www.afmc.ca/pdf/fmec/21 Steinert_Faculty\%20Development.pdf (accessed August 2016).

7. Steinert Y, Mann K, Centeno A, et al. A systematic review of faculty development initiatives designed to improve teaching effectiveness in medical education: BEME Guide No. 8. Med Teach 2006; 28: 497-526.

8. Holmboe ES, Sherbino J, Long DM, Swing SR, Frank JR. The role of assessment in competency-based medical education. Med Teach 2010; 32: 676-82.

9. Pickworth GE, Snyman WD. Changing assessment practice through in situ faculty development. Eur J Dent Educ 2012; 16: e59-63.

10. Snell LS, Frank JR. Competencies, the tea bag model, and the end of time. Med Teach 2010; 32: 629-30.

11. Dornan T. Osler, Flexner, apprenticeship and the new medical education'. J R Soc Med 2005; 98: 91-5.

12. Holmboe ES, Hawkins RE, Huot SJ. Effects of training in direct observation of medical residents' clinical competence: a randomized trial. Ann Intern Med 2004; 140: 874-81.

13. Royal College of Physicians and Surgeons of Canada. CanMEDS: Better standards, better physicians, better care. Available from URL: http://www.royalcollege.ca/rcsite/ canmeds/canmeds-framework-e (accessed August 2016).

14. Carraccio $C$, Englander $R$, Van Melle $E$, et al. Advancing competency-based medical education: a charter for clinicianeducators. Acad Med 2016; 91: 645-9.

15. Harris DL, Krause KC, Parish DC, Smith MU. Academic competencies for medical faculty. Fam Med 2007; 39: 343-50. 
16. Sterkenburg A, Barach P, Kalkman C, Gielen M, ten Cate O. When do supervising physicians decide to entrust residents with unsupervised tasks? Acad Med 2010; 85: 1408-17.

17. Holmboe ES. Faculty and the observation of trainees' clinical skills: problems and opportunities. Acad Med 2004; 79: 16-22.

18. Green MR, Holmboe E. Perspective: the ACGME toolbox: half empty or half full? Acad Med 2010; 85: 787-90.

19. Kogan JR, Conforti LN, Bernabeo EC, Durning SJ, Hauer KE, Holmboe ES. Faculty staff perceptions of feedback to residents after direct observation of clinical skills. Med Educ 2012; 46: 201-15.

20. Albanese MA, Mejicano G, Anderson WM, Gruppen L. Building a competency-based curriculum: the agony and the ecstasy. Adv Health Sci Theory Pract 2010; 15: 439-54.

21. Spadafora SM, Houston P, Levine M. A national curriculum in anesthesia: rationale, development, implementation, and implications. Can J Anesth 2012; 59: 636-41.

22. Taber S, Frank JR, Harris KA, Glasgow NJ, Iobst W, Talbot M. Identifying the policy implications of competency-based education. Med Teach 2010; 32: 687-91.

23. Ankel F, Franzen D, Frank J. Milestones: quo vadis? Acad Emerg Med 2013; 20: 749-50.

24. Chacko TV. Moving toward competency-based education: challenges and the way forward. Arch Med Health Sci 2014; 2: 247-53.

25. Gercama A, van Lankveld T, Kleinveld J, Croiset G, Kusurkar R. Bridging the gap between CBME in theory and practice: the role of a teacher community. Perspect Med Educ 2014; 3: 486-91.

26. McGaghie WC, Miller GE, Sajid AW, Telder TV. Competencybased curriculum development in medical education: an introduction. Public Health Pap 1978; 68: 11-91.

27. Holmboe ES, Ward DS, Reznick RK, et al. Faculty development in assessment: the missing link in competency-based medical education. Acad Med 2011; 86: 460-7.

28. Iobst WF, Sherbino J, ten Cate OT, et al. Competency-based medical education in postgraduate medical education. Med Teach 2010; 32: 651-6.

29. Vukanovic-Criley JM, Criley S, Warde CM, et al. Competency in cardiac examination skills in medical students, trainees, physicians, and faculty: a multicenter study. Arch Intern Med 2006; 166: 610-6.

30. Braddock $C H$ 3rd, Edwards KA, Hasenberg NM, Laidley $T L$, Levinson $W$. Informed decision making in outpatient practice: time to get back to basics. JAMA 1999; 282: 2313-20.
31. Teherani A, Chen HC. The next steps in competency-based medical education: milestones, entrustable professional activities and observable practice activities. J Gen Intern Med 2014; 29: 1090-2.

32. Carraccio $C L$, Englander $R$. From Flexner to competencies: reflections on a decade and the journey ahead. Acad Med 2013; 88: 1067-73.

33. Kogan JR, Hess BJ, Conforti LN, Holmboe ES. What drives faculty ratings of residents' clinical skills? The impact of faculty's own clinical skills. Acad Med 2010; 85: S25-8.

34. Frank JR, Snell LS, Sherbino J. Draft CanMEDS 2015 Physician Competency Framework-Series III. Ottawa: The Royal College of Physicians and Surgeons of Canada; 2014. Available from URL: http://www.royalcollege.ca/rcsite/documents/canmeds/canmeds2015-framework-series-3-e.pdf (accessed August 2016).

35. Arora S, Sevdalis N, Suliman I, Athanasiou T, Kneebone R, Darzi $A$. What makes a competent surgeon?: Experts' and trainees' perceptions of the roles of a surgeon. J Surg 2009; 198: 726-32.

36. Bligh J. Faculty development. Med Educ 2005; 39: 120-1.

37. Crossan MM, Rouse MM, Fry JN, Killing JP. Strategic Analysis and Action. 8th ed. Don Mills: Pearson Canada Inc.; 2013 .

38. Royal College of Physicians and Surgeons of Canada. About Milestones and EPAs. Available from URL: http://www. royalcollege.ca/rcsite/cbd/milestones-entrustable-professionalacts-epas-e (accessed August 2016).

39. Lurie SJ, Mooney CJ, Lyness JM. Measurement of the general competencies of the accreditation council for graduate medical education: a systematic review. Acad Med 2009; 84: 301-9.

40. Steinert $Y$, Mann $K V$. Faculty development: principles and practices. J Vet Med Educ 2006; 33: 317-24.

41. Inui TS, Williams WJ Jr, Goode L, et al. Sustaining the development of primary care in academic medicine. Working Group on Sustaining the Development of Academic Primary Care. Association of American Medical Colleges. Acad Med 1998; 73: 245-57.

42. Swing SR, Clyman SG, Holmboe ES, Williams RG. Advancing resident assessment in graduate medical education. J Grad Med Educ 2009; 1: 278-86.

43. Narayan AP, Whicker SA, McGann KA. An innovative process for faculty development in residency training. Teach Learn Med 2012; 24: 248-56.

44. Hawkins RE, Welcher CM, Holmboe ES, et al. Implementation of competency-based medical education: are we addressing the concerns and challenges? Med Educ 2015; 49: 1086-102. 